\title{
Guided and Direct Wave Evaluation of Controlled Source Electromagnetic Survey Using Finite Element Method
}

\author{
Noorhana Yahya ${ }^{1}$, Majid Niaz Akhtar ${ }^{2}$, Nadeem Nasir², Muhammad Kashif ${ }^{2}$, Afza Shafie ${ }^{1}$, \\ Hasnah Mohd Zaid ${ }^{1}$ \\ ${ }^{1}$ Fundamental and Applied Sciences Department, Bandar Seri Iskandar, Tronoh, Malaysia; ${ }^{2}$ Electrical and Electronic Engineering \\ Department, Universiti Teknologi PETRONAS, Bandar Seri Iskandar, Tronoh, Malaysia. \\ Email: majidniazakhtar@gmail.com
}

Received January $15^{\text {th }}$, 2012; revised February $14^{\text {th }}$, 2012; accepted February $24^{\text {th }}, 2012$

\begin{abstract}
Deep target hydrocarbon detection is still challenging and expensive. Direct hydrocarbon indicators (DHIs) in seismic data do not correspond to economical hydrocarbon exploration. Due to unreliability in seismic data for the detection of DHIs, new methods have been investigated. Marine controlled source electromagnet (MCSEM) or Sea bed logging (SBL) is new method for the detection of deep target hydrocarbon reservoir. Sea bed logging has also the potential to reduce the risks of DHIs in deep sea environment. Modelling of real sea environment helps to reduce the further risks before drilling the oil wells. 3D electromagnetic (EM) modelling of seabed logging requires more accurate methods for the detection of hydrocarbon reservoir. Finite element method (FEM) is chosen for the modelling of seabed logging to get more precise EM response from hydrocarbon reservoir below $4000 \mathrm{~m}$ from seabed. FEM allows to investigate the total electric and magnetic fields instead of scattered electric and magnetic fields, which shows accurate and precise resistivity contrast below the seabed. From the modelling results, It was investigated that $\mathrm{Hz}$ field shows higher magnitude with 342\% than the Ex field. It was observed that $0.125 \mathrm{~Hz}$ frequency can be able to show better resistivity contrast of $\mathrm{Hz}$ field (31.30\%) and Ex field (16.49\%) at target depth of $1000 \mathrm{~m}$ below seafloor for our proposed model. $\mathrm{Hz}$ and Ex field delineation was found to decrease as target depth increased from $1000 \mathrm{~m}$ to $4000 \mathrm{~m}$. At the target depth of 4000 $\mathrm{m}$, no field delineation response was seen from the current electromagnetic (EM) antenna used by the industry. New EM antenna has been used to see the EM response for deep target hydrocarbon detection. It was investigated that novel EM antenna shows better delineation at $4000 \mathrm{~m}$ target depth for Ex and $\mathrm{Hz}$ field up to $10.3 \%$ and $15.1 \%$ respectively. Novel EM antenna also shows better $\mathrm{Hz}$ phase response (128.4\%) than the Ex phase response (38.3\%) at the target depth of $4000 \mathrm{~m}$ below the seafloor.
\end{abstract}

Keywords: Sea Bed Logging; Controlled Source Electromagnetic (CSEM); Electromagnetic (EM) Antenna and Finite Element Method

\section{Introduction}

Marine controlled source electromagnetic (MCSEM) surveying has become promising tool for remotely detecting, characterizing and mapping offshore hydrocarbon reservoirs. MCSEM survey has an advantage over seismic method due to low cost, accurate and economic for shallow as well as deep target [1,2]. MCSEM method also referred as seabed logging uses EM transmitter for the transmission of EM waves into marine environment. EM receivers are placed on seabed to record the EM waves after reflected, refracted and guided back from different resistive layers such as sediments and hydrocarbon. Low frequency EM waves ranges from (0.01 to $10 \mathrm{~Hz}$ ) has been used for the detection of hydrocarbon reservoir situated at different depths below seabed $[3,4]$.
Sea bed logging involves certain limitations such as sea water depth, complex geological layers, source receiver geometry and source signal strength etc. For the deep water and deep target environment, there is no air wave effect. In deep target environment, the EM waves after guided back from the hydrocarbon reservoir has weak strength and difficult for the receiver to detect EM signal. The signal strength can be increased by modifying transmitting antenna. Conventional magnetic feeders (Magnetic frills), which was constructed by a toroid coil on a ferrite magnetic feeder were used for the excitation of long wire antenna. It was observed that magnetic feeders have ability to excite the TM wave field components such as $\mathrm{Ez}, \mathrm{H} \phi$, and E $\rho$. It was also investigated that when the magnetic feeders are used on the antenna, the magnetic flux energy will transfer from magnetic feeders 
to current flowing along the antenna. Higher the Q values can give higher efficiency of power. It was also observed that hysteresis losses and eddy current losses increases as the frequency increases [5,6]. Magnitude of EM waves increased by using magnetic feeders on the antenna was also investigated $[7,8]$. It was found that magnitude of EM waves can be increased up to $243 \%$ using magnetic feeders on the antenna in lab scale environment [9]. Electric field response from different gas hydrate models were investigated by exciting horizontal electric dipole source. MCSEM method requires modelling tools for the characterizing, mapping and detection of hydrocarbon reservoir. Different numerical modelling tools such as Finite element method (FEM), Finite difference method (FDM), Transmission line matrix (TLM) method, Method of moment (MOM), Boundary element method (BEM) etc. [10]. Finite element method is a versatile technique to find approximate solution of partial differential equations (PDE) as well as integral equations. Finite element method uses Maxwell's equations for the solution of electromagnetic (EM) problems. FEM method investigated detailed visualization of resistive layers in MCSEM environment [11]. The effect of different values of transmitting frequency from the source, distance between the source and the seabed, water depth and thickness of overburden layer was observed during the study [12].

\section{Theoretical Background}

Finite element method has been used to solve CSEM problems. Maxwell's equations were solved using coulomb gauged EM potentials where as sparse system of linear equations was solved by using Quasi minimal residual method. It was also investigated that finite element is a general method and can be easily applied for CSEM modelling [13].

In finite element method (FEM), Galerkin method minimizes the errors over the entire volume of the proposed model. It was studied that FEM has not required quasi static approximation. FEM can be easily applied to the complex and homogenous structures due to Galerkin approximation [14]. FEM uses the process of discretization of the region by creating meshes. Meshing is used to subdivide a large geometry into a number of non overlapping sub regions. It is necessary to discretize physical structure regular or irregular into finite number of degrees of freedom. Finite element method (FEM) can be easily applied to arbitrarily geological structures due to unstructured meshes. Finite element (FE) modelling results show less than 1\% error as compared to Finite difference time domain (FDTD) and Method of moment (MoM) etc. [15]. Modelling of geophysical electromagnetic methods by finite element has been discussed by $[16,17]$. The electric and magnetic field differential equations for the solution of EM problem are

$$
\begin{aligned}
& \frac{\partial^{2} E_{x}}{\partial y^{2}}+i \omega \mu_{0} \sigma(y) E_{x}=0 \\
& \frac{\partial^{2} H_{z}}{\partial y^{2}}+i \omega \mu_{0} \sigma(y) H_{z}=0
\end{aligned}
$$

In finite element method, explicit specification of approximate electric field is

$$
\begin{aligned}
& E_{x}(y)=\sum_{i=1}^{N} E_{i} \phi_{i}(y) \\
& E_{z}(y)=\sum_{i=1}^{N} E_{i} \phi_{i}(y)
\end{aligned}
$$

where,

$\phi_{i}(y)$ are the basis functions, whereas $E_{i}$ and $H_{i}$ are the coefficients of approximate electric and magnetic field in this expression.

$$
\phi_{i}(y)=\left[\begin{array}{l}
\left(y-y_{i}\right) /\left(y_{i}-y_{i-1}\right), y_{i-1} \leq y \leq y_{i} \\
\left(y_{i+1}-y\right) /\left(y_{i+1}-y_{i}\right), y_{i} \leq y \leq y_{i+1} \\
0 \rightarrow \text { otherwise }
\end{array}\right]
$$

Approximate electric field is linear between each pair of nodes where as it has continues value at each node. For the solution of true electric field, the approximate electric and magnetic fields are

$$
\sum_{i=1}^{N} E_{i}\left\{\frac{\partial^{2} \phi_{i}}{\partial y^{2}}+i \omega \mu_{0} \sigma(y) \phi_{i}\right\}+R=0
$$

and

$$
\sum_{i=1}^{N} H_{i}\left\{\frac{\partial^{2} \phi_{i}}{\partial y^{2}}+i \omega \mu_{0} \sigma(y) \phi_{i}\right\}+R=0
$$

where,

$R$ is residual due to applied electric or magnetic field, $\psi_{j}$ is weight functions. The electric field equation is

$$
\begin{gathered}
\sum_{i=1}^{N} E_{i}\left\{\psi_{j} \frac{\partial^{2} \phi_{i}}{\partial y^{2}}+i \omega \mu_{0} \sigma(y) \psi_{j} \phi_{i}\right\}+\psi_{j} R=0 \\
\sum_{i=1}^{N} E_{i}\left\{\int_{y_{1}}^{y_{N}} \psi_{j} \frac{\partial^{2} \phi_{i}}{\partial y^{2}} \mathrm{~d} y+i \omega \mu_{0} \int_{y_{1}}^{y_{N}} \sigma \psi_{j} \phi \mathrm{d} y\right\}+\int_{i}^{y_{N}} \psi_{j} R \mathrm{~d} y=0 \text { (7) }
\end{gathered}
$$

$R$ is orthogonal to weight function $\psi_{j}$

$$
\int_{y_{1}}^{y_{N}} \psi_{j} R \mathrm{~d} y=0
$$

In finite element method two main perspectives have been considered. One is variational method and other is method of weighted residuals. Method of weighted residual has advantage to solve partial differential equations with greater accuracy and minimize error than variational method. Galerkin method used method of weighted residual 
to solve electromagnetic problem by FEM. In Galerkin method, basis functions are used as weight functions, which make square system with $N$ equations in $N$ unknowns.

$$
\begin{gathered}
\sum_{i=1}^{N} E_{i}\left\{\int_{y_{1}}^{y_{N}} \phi_{j} \frac{\partial^{2} \phi_{i}}{\partial y^{2}} \mathrm{~d} y+i \omega \mu_{0} \int_{y_{1}}^{y_{N}} \sigma \phi_{j} \phi_{i} \mathrm{~d} y\right\}=0 \\
\int_{y_{1}}^{y_{i+1}} \phi_{j} \frac{\partial^{2} \phi_{i}}{\partial y^{2}} \mathrm{~d} y=-\int_{y_{1}}^{y_{i+1}} \frac{\partial \phi_{j}}{\partial y} \frac{\partial \phi_{i}}{\partial y} \mathrm{~d} y+\left.\left(\phi_{j} \frac{\partial \phi_{i}}{\partial y}\right)\right|_{y_{1}} ^{y_{i+1}}
\end{gathered}
$$

As basis functions are continues, then using Galerkin method, weight function will be continues.

$$
\begin{gathered}
\int_{y_{1}}^{y_{i+1}} \phi_{j} \frac{\partial^{2} \phi_{i}}{\partial y^{2}} \mathrm{~d} y=-\int_{y_{1}}^{y_{i+1}} \frac{\partial \phi_{j}}{\partial y} \frac{\partial \phi_{i}}{\partial y} \mathrm{~d} y \\
\sum_{i=1}^{N}\left\{\int_{y_{1}}^{y_{N}} \frac{\partial \phi_{j}}{\partial y} \frac{\partial \phi_{i}}{\partial y} \mathrm{~d} y+i \omega \mu_{0} \int_{y_{1}}^{y_{N}} \sigma \phi_{j} \phi_{i} \mathrm{~d} y\right\} E_{i}=0
\end{gathered}
$$

Similarly, the magnetic field equation can be written as

$$
\begin{gathered}
\sum_{i=1}^{N}\left\{\int_{y_{1}}^{y_{N}} \frac{\partial \phi_{j}}{\partial y} \frac{\partial \phi_{i}}{\partial y} \mathrm{~d} y+i \omega \mu_{0} \int_{y_{1}}^{y_{N}} \sigma \phi_{j} \phi_{i} \mathrm{~d} y\right\} H_{i}=0 \\
\left(L+i \omega \mu_{0} S\right) \boldsymbol{E}=r \\
\left(L+i \omega \mu_{0} S\right) \boldsymbol{H}=r
\end{gathered}
$$

$\boldsymbol{E}$ and $\boldsymbol{H}$ are the vectors containing coefficient for each node in finite element (FE) expression for approximate electric and magnetic fields,

$$
\boldsymbol{L}_{j i}=\int_{y_{1}}^{y_{N}} \frac{\partial \phi_{j}}{\partial y} \frac{\partial \phi_{i}}{\partial y} \mathrm{~d} y \quad \boldsymbol{S}_{j i}=\int_{y_{1}}^{y_{N}} \sigma \phi_{j} \phi_{i} \mathrm{~d} y
$$

$\boldsymbol{L}$ and $\boldsymbol{S}$ are $N \times N$ matrices. By solving these matrices, electric field can be solved straight forward for 1D electromagnetic (EM) problem. For EM problems a large number of equations with many matrices need to be solved. Different commercial soft wares have been used to study the EM geological problems.

The current study is about the modelling of real seabed environment by using conventional EM antenna and novel EM antenna for deep target hydrocarbon detection. Comsol multiphysics based on finite element method have been used to solve deep target problem. All field components (Ex, Ey and $\mathrm{Ez}$ ) and ( $\mathrm{Hx}, \mathrm{Hy}$ and $\mathrm{Hz}$ ) with and without hydrocarbon were also compared during the study. Magnitude of $\mathrm{E}$ field and $\mathrm{H}$ field response from resistive layers was also compared during the study. Section 3 will describe about the methodology adapted to achieve the objectives. In Section 4, results obtained using conventional and new Electromagnetic antenna will be discussed in detail.

\section{Methodology}

Finite element method (FEM) was used to detect hydrocarbon below several hundred of meters from seabed. (Comsol Multiphysics-3.5a) based on finite element method (FEM) was used to simulate area of the seabed model contains $40 \times 40 \mathrm{~km}$. Seabed model with air thickness $500 \mathrm{~m}$, sea water depth $1000 \mathrm{~m}$, overburden $1000 \mathrm{~m}$, hydrocarbon thickness $100 \mathrm{~m}$ and under burden thickness $3500 \mathrm{~m}$ was constructed. $0.125 \mathrm{~Hz}$ frequency with $1250 \mathrm{~A}$ current was used at the transmitter. Different models were simulated after increasing target depth of $500 \mathrm{~m}$ from 1000 to $400 \mathrm{~m}$ below seafloor. The position of the antenna was $30 \mathrm{~m}$ above the seafloor. The length of the antenna was kept $270 \mathrm{~m}$. The frequency was decreased from $0.125 \mathrm{~Hz}$ to $0.0625 \mathrm{~Hz}$ and current was increased from 1250 A to 7200 A at 4000 m target depth. New EM antenna with magnetic feeders was used in our proposed model to get better delineation response at target depth of $4000 \mathrm{~m}$. Triangular meshes with free mesh parameter of $1.0 \mathrm{e}-3$ were selected. Refined meshes were also used to get more precise and accurate results. Sub domain settings with conductivity and relative permittivity of air, sea water, under burden, overburden and hydrocarbon were adjusted as given in Table 1. Boundary conditions were adjusted on the proposed seabed model to get the electric and magnetic response. Partial differential equations for magnetic and electric fields in the wave number domain were also used to get total electric and magnetic field response with and without hydrocarbon. Figure 1 shows schematic diagram of seabed model with transmitter and receivers on the seabed.

Table 1. Relative permittivity, conductivity values of air, sea water and hydrocarbon.

\begin{tabular}{ccccc}
\hline & Air & Sea water & $\begin{array}{c}\text { Under-burden } \\
\text { /Overburden }\end{array}$ & $\begin{array}{c}\text { Hydrocarbon } \\
\text { (Oil) }\end{array}$ \\
\hline$\varepsilon r$ & 1.006 & 80 & 30 & 4 \\
$\sigma$ & $1.0 \mathrm{e}-13$ & 3 & 1.5 & 0.001 \\
\hline
\end{tabular}

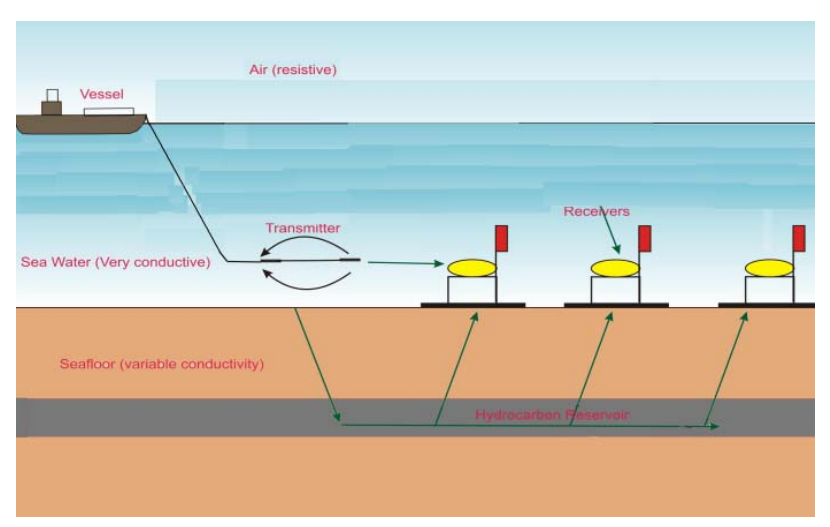

Figure 1. Schematic diagram of seabed model. 


\section{Results and Discussions}

Finite element method is used to simulate the CSEM experiment on our proposed seabed model. Figure 2 shows finite element method applied on proposed seabed model. The finite element generates meshes on the proposed model to get the EM response from the marine environment such as seawater, overburden, under burden and hydrocarbon etc. Finite element creates refined meshes with thousands of interconnecting nodes. More refined meshes at the transmitter and receiver especially for small transmitter and receiver offsets were used to get more precise and accurate results [18]. Figures 3(a)-(c) show Ey, Ez and Ex field response with and without hydrocarbon located at $1000 \mathrm{~m}$ below the seafloor respectively. It was found that Ey and Ez components have no ability for the detection of hydrocarbon in our proposed seabed model. It was observed that Ex component gives better response in terms of magnitude and delineation as compared to other two components Ey and Ez. Ex component gave smooth and better response due to propagation of EM waves in y-direction from inline orientation of EM transmitter. Table 2 shows the comparison of Ey, Ez and Ex field components with and without HC at target depth of $1000 \mathrm{~m}$ below seabed.

Figures 4(a)-(c) show $\mathrm{Hx}$, $\mathrm{Hy}$ and $\mathrm{Hz}$ field response with and without hydrocarbon located at $1000 \mathrm{~m}$ below the seafloor respectively. It was found that $\mathrm{Hx}$ and $\mathrm{Hy}$ components have no ability for the detection of hydrocarbon in our proposed seabed model. It was observed that $\mathrm{Hz}$ component gives better response in terms of magnitude and delineation as compared to other two components $\mathrm{Hy}$ and $\mathrm{Hx}$. Hz component gave smooth and better response due to propagation of EM waves in y-direction from inline orientation of EM transmitter. Table 3 shows the comparison of $\mathrm{Hx}$, Hy and $\mathrm{Hz}$ field components with and without $\mathrm{HC}$ at target depth of 1000 $\mathrm{m}$ below seabed. It can be seen that $\mathrm{Ex}$ and $\mathrm{Hz}$ field components show delineation response than all the other components, where as $\mathrm{Hz}$ field gave better delineation (31.3\%) than Ex field component (16.4\%) at target depth of $1000 \mathrm{~m}$ below seabed. It was also investigated that $\mathrm{Hz}$ field gave higher magnitude with better delineation as compared to Ex field component.

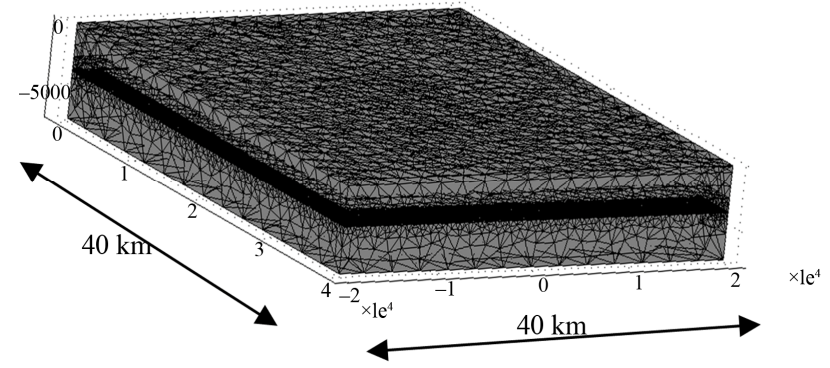

Figure 2. Seabed logging model with meshes generated by FEM.
Figures 5(a)-(g) show normalized E field response with and without hydrocarbon located at $1000 \mathrm{~m}, 1500 \mathrm{~m}$, $2000 \mathrm{~m}, 2500 \mathrm{~m}, 3000 \mathrm{~m}, 3500 \mathrm{~m}$ and $4000 \mathrm{~m}$ below the seafloor respectively. It was found that normalized $\mathrm{E}$

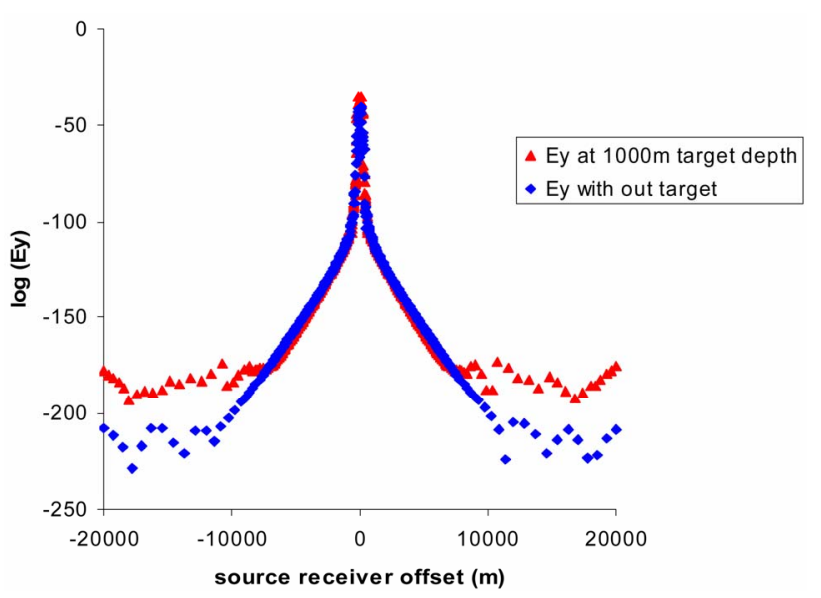

(a)

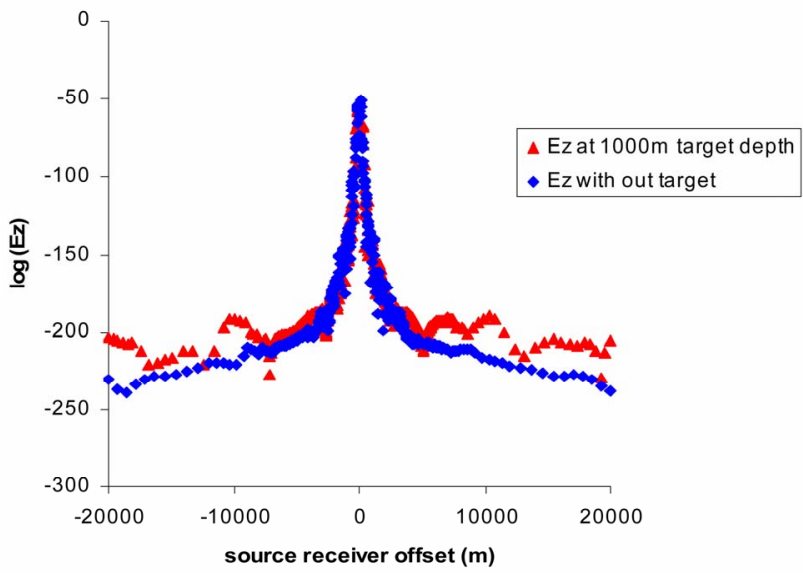

(b)

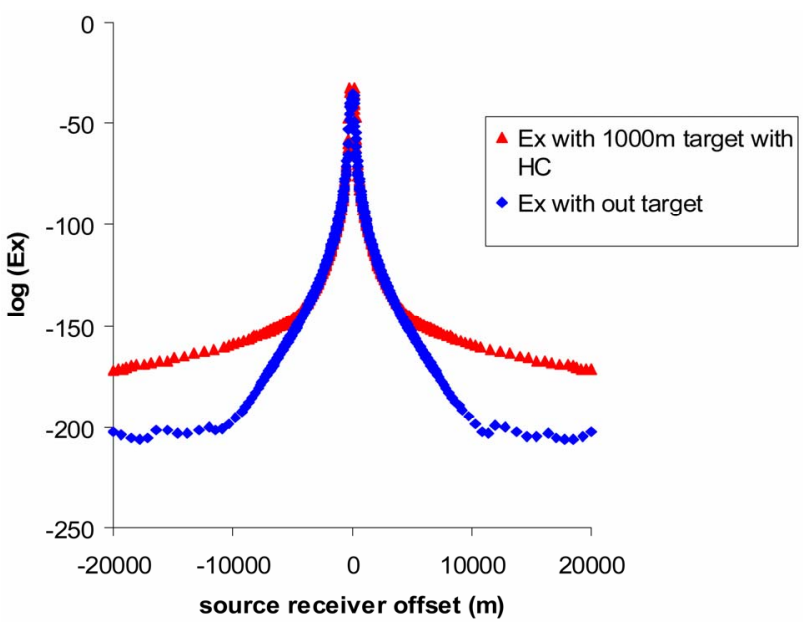

(c)

Figure 3. Log (E) components vs source receiver offset (a) Ey component; (b) Ez component; (c) Ex component with and without $\mathrm{HC}$ at $1000 \mathrm{~m}$ target depth from seabed. 
Table 2. Ex, Ey and Ez components at $1000 \mathrm{~m}$ target depth at $0.125 \mathrm{~Hz}$ frequency with $1250 \mathrm{~A}$ current at transmitter.

\begin{tabular}{|c|c|c|c|}
\hline \multirow{2}{*}{$\begin{array}{l}\text { Target } \\
\text { depth }\end{array}$} & Ey field & Ez field & Ex field \\
\hline & \multicolumn{3}{|c|}{ with and without hydrocarbon } \\
\hline $1000 \mathrm{~m}$ & $5.89 \%$ & $2.24 \%$ & $16.49 \%$ \\
\hline
\end{tabular}

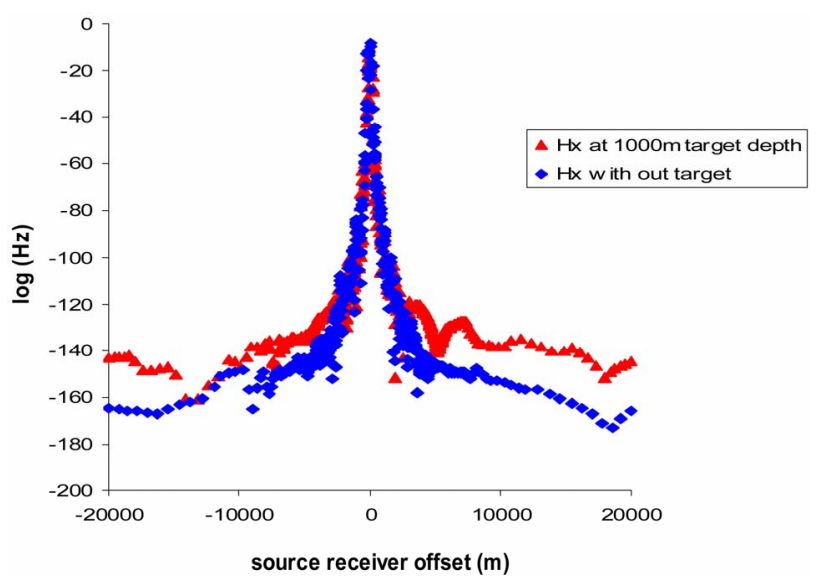

(a)

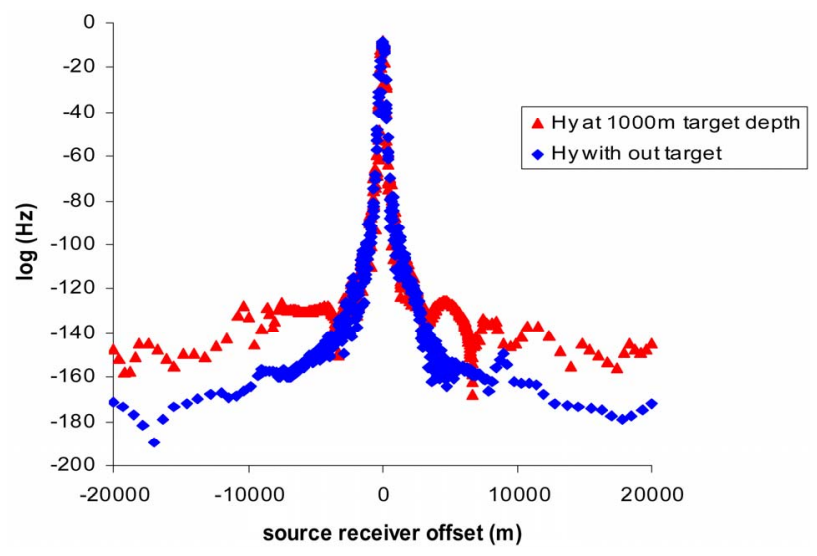

(b)

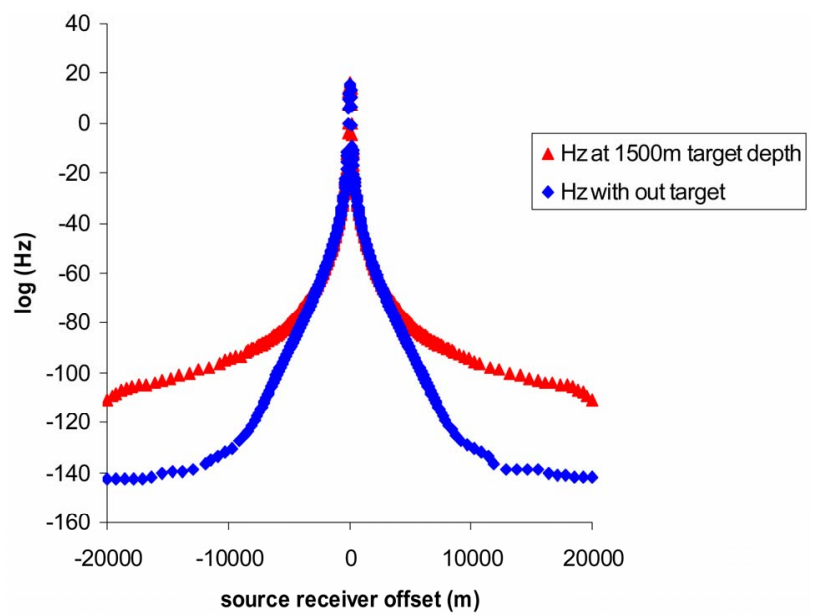

(c)

Figure 4. Log (H) components vs source receiver offset (a) Hx component; (b) Hy component; (c) Hz component with and without $\mathrm{HC}$ at $1000 \mathrm{~m}$ target depth from seabed.
Table 3. Hx, Hy and $\mathrm{Hz}$ components at $1000 \mathrm{~m}$ target depth at $0.125 \mathrm{~Hz}$ frequency with $1250 \mathrm{~A}$ current at transmitter.

\begin{tabular}{cccc}
\hline Target & Hy field & Hz field & Hx field \\
\cline { 2 - 3 } depth & \multicolumn{3}{c}{ with and without hydrocarbon } \\
$1000 \mathrm{~m}$ & $5.68 \%$ & $7.16 \%$ & $31.3 \%$ \\
\hline
\end{tabular}

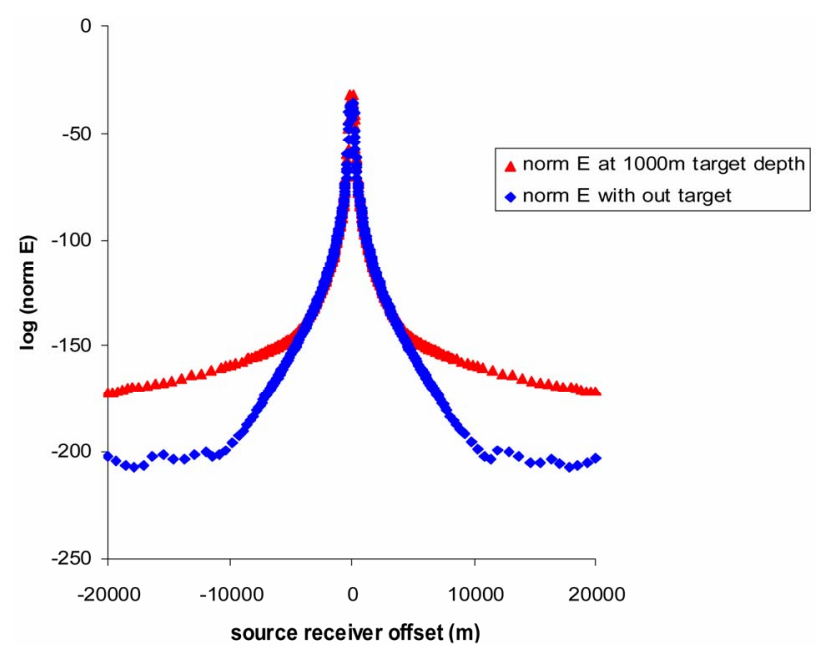

(a)

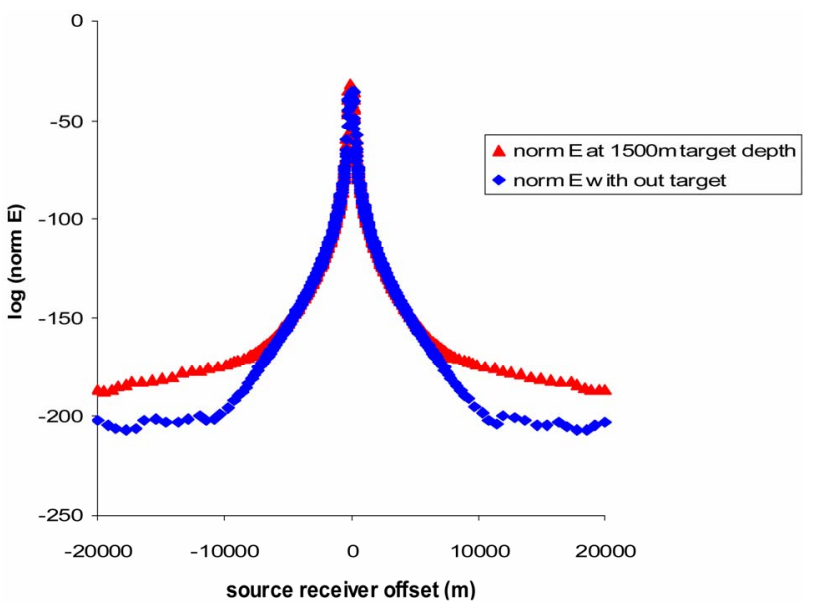

(b)

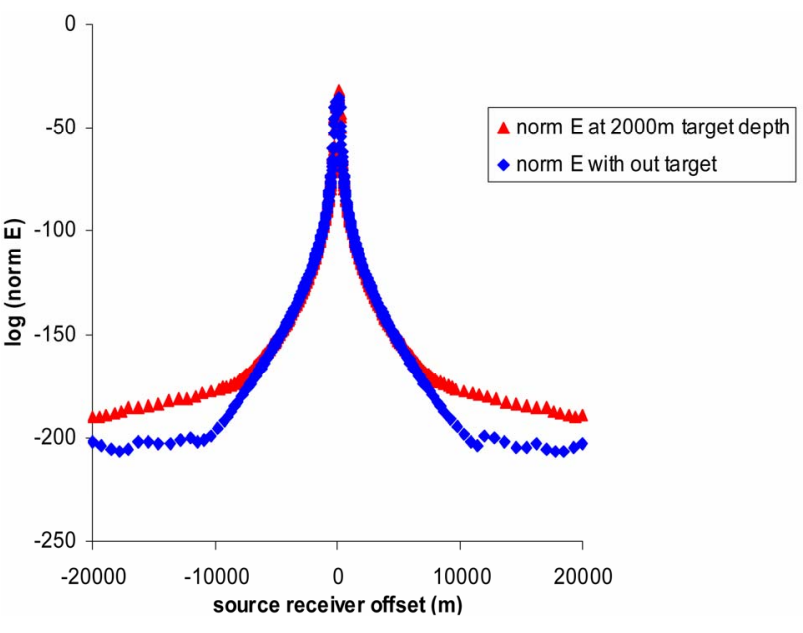

(c) 


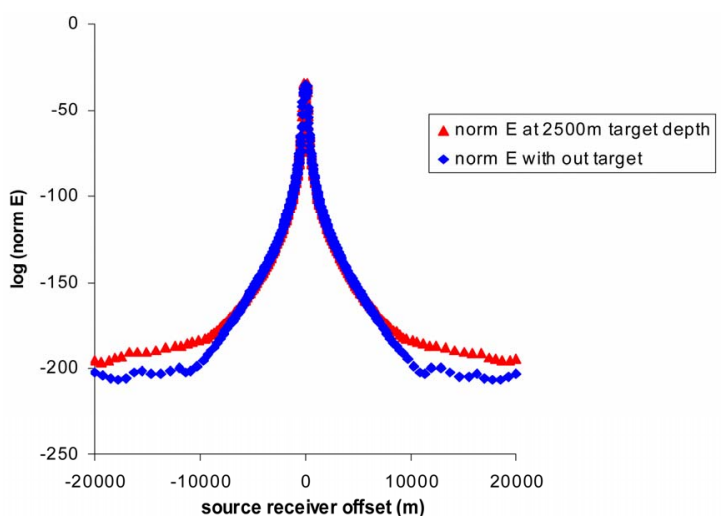

(d)

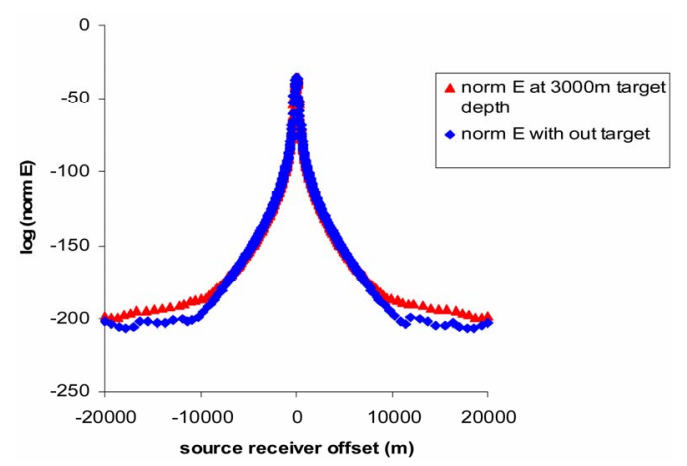

(e)

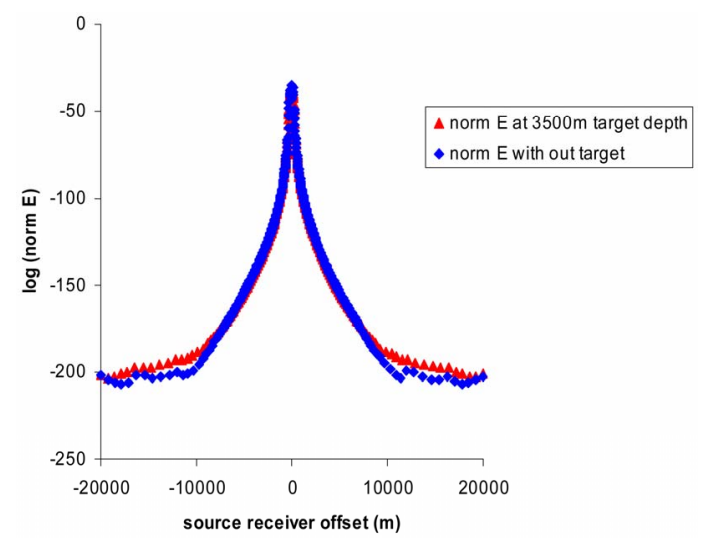

(f)

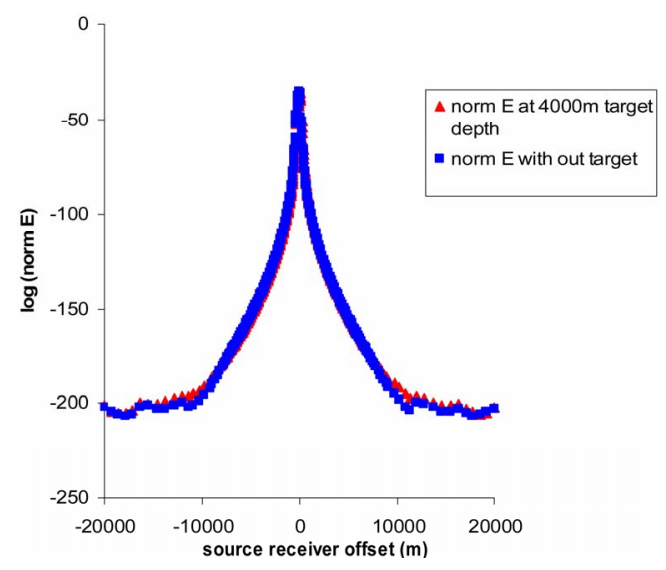

(g)

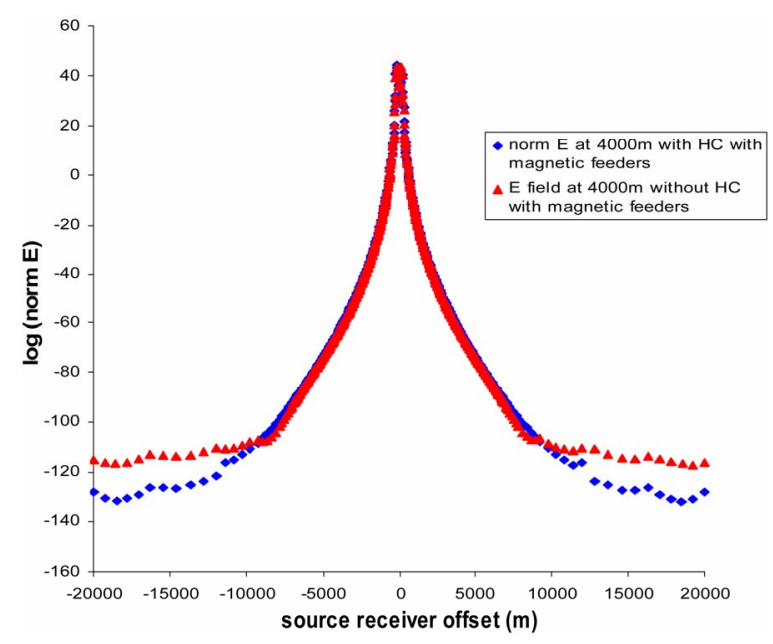

(h)

Figure 5. Magnitude of $H$ field verses source receiver offset with and without HC at (a) $1000 \mathrm{~m}$; (b) $1500 \mathrm{~m}$; (c) $2000 \mathrm{~m}$; (d) $2500 \mathrm{~m}$; (e) $3000 \mathrm{~m}$; (f) $3500 \mathrm{~m}$; (g) $4000 \mathrm{~m}$; at $0.125 \mathrm{~Hz}$; (h) with 9 magnetic feeders using finite element method.

field at the offset decreased as the depth increased from $1000 \mathrm{~m}$ to $4000 \mathrm{~m}$. It can be seen that at target depth of $1000 \mathrm{~m}$ normalized E field response was $16.49 \%$ but as the depth increased up to $4000 \mathrm{~m}$, E field response decreased up to $(1.10 \%)$. Comparison of percentage of normalized E field with and without hydrocarbon with different target depths are given in Table 4. It was found that at $4000 \mathrm{~m}$ target depth with $0.125 \mathrm{~Hz}$ frequency and 1250 A current, it was not possible to see the hydrocarbon. The frequency was decreased from $0.125 \mathrm{~Hz}$ to $0.0625 \mathrm{~Hz}$ at $1250 \mathrm{~A}$; the delineation response of $2.84 \%$ was investigated. The increase of current from $1250 \mathrm{~A}$ to 7200 A at target depth of $4000 \mathrm{~m}$ target depth, we get normalized E field response up to $2.45 \%$ with and without HC. The decrease in frequency from $0.125 \mathrm{~Hz}$ to $0.0625 \mathrm{~Hz}$ gives us delineation but resolution will be not good at the low frequency. Novel EM antenna with 3, 6 and 9 magnetic feeders was used for deep hydrocarbon survey. EM antenna with 9 magnetic feeders has shown promising results for the direct hydrocarbon detection below $4000 \mathrm{~m}$ from the seabed (Figure 5(h)). It was investigated that by using 9 magnetic feeders at the antenna, we can get better delineation up to $10.3 \%$ (Table 4).

Guided response of electromagnetic waves from hydrocarbon was also investigated. It was observed that direct response of electromagnetic waves were detected by the receivers on the seafloor was up to $3 \mathrm{~km}$. After 3 $\mathrm{km}$ guided response was detected by the receivers. The guided response starts from $3.5 \mathrm{~km}$ to $18 \mathrm{~km}$ where as refracted and reflected wave response can be seen at far offset above $18 \mathrm{~km}$. Figure 6(a) shows the EM response (direct, guided and reflected or refracted) at the target depth 1000 m below seafloor. The greater guided response 
Table 4. Comparison of percentage of magnitude of Ex and $\mathrm{Hz}$ field and phase with and without hydrocarbon at different target depth.

\begin{tabular}{ccccccc}
\hline \multirow{2}{*}{$\begin{array}{c}\text { Target } \\
\text { depth (m) }\end{array}$} & \multirow{2}{*}{$\begin{array}{c}\text { Frequency } \\
\text { (Hz) }\end{array}$} & Current & \multicolumn{3}{c}{ Ex field } & \multicolumn{4}{c}{ Ex phase } & Hz field & Hz phase \\
\cline { 5 - 8 } & & & \multicolumn{2}{c}{ with and without hydrocarbon } \\
\hline 1000 & 0.1250 & 1250 & 16.4 & 78.7 & 31.3 & 164.3 \\
1500 & 0.1250 & 1250 & 10.4 & 42.1 & 16.3 & 139.5 \\
2000 & 0.1250 & 1250 & 6.74 & 26.6 & 9.74 & 123.1 \\
2500 & 0.1250 & 1250 & 5.15 & 17.5 & 7.73 & 48.7 \\
3000 & 0.1250 & 1250 & 3.58 & 7.04 & 5.12 & 18.0 \\
3500 & 0.1250 & 1250 & 2.94 & 5.03 & 3.46 & 7.95 \\
4000 & 0.1250 & 1250 & 1.10 & 3.64 & 2.54 & 4.04 \\
4000 & 0.0625 & 1250 & 2.84 & 3.27 & 3.82 & 4.01 \\
\hline
\end{tabular}

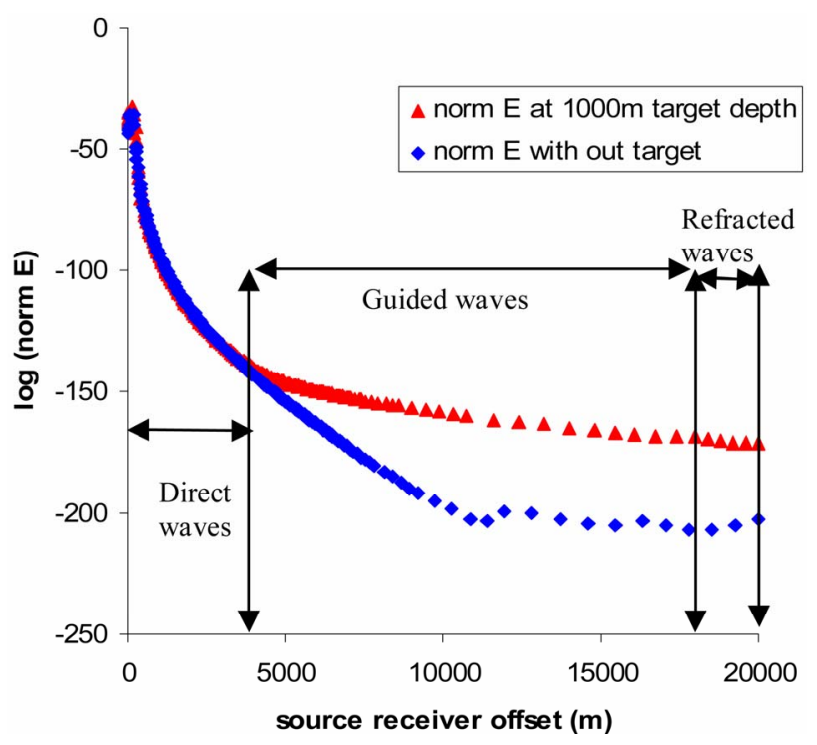

(a)

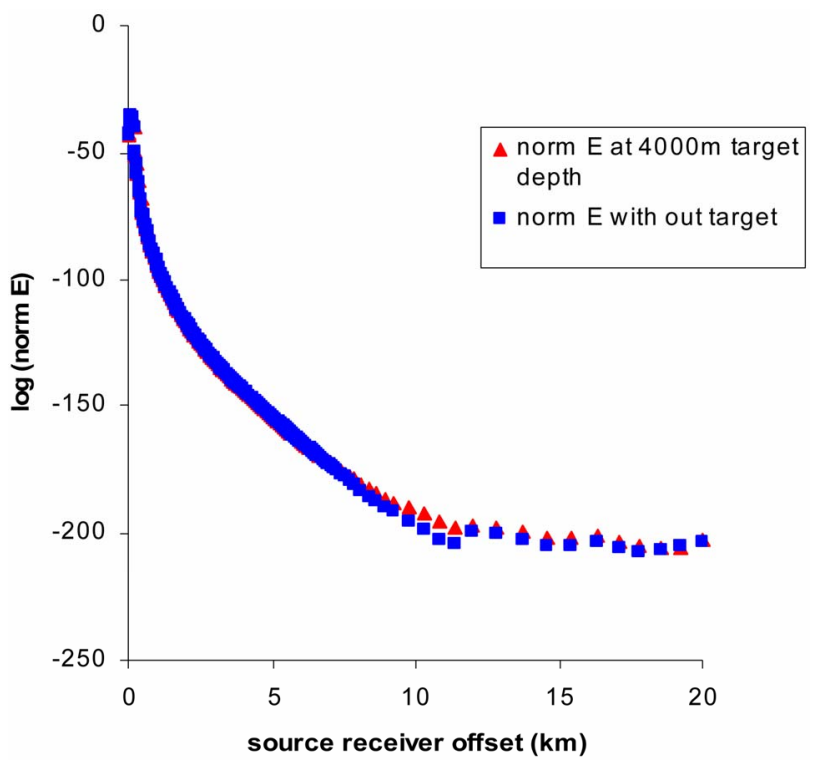

(b)

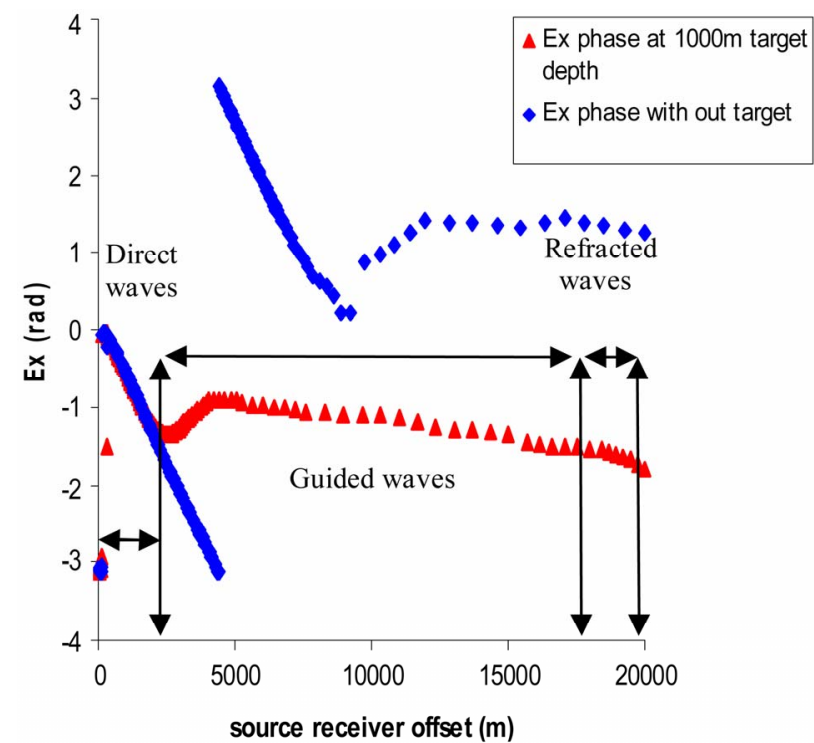

(c)

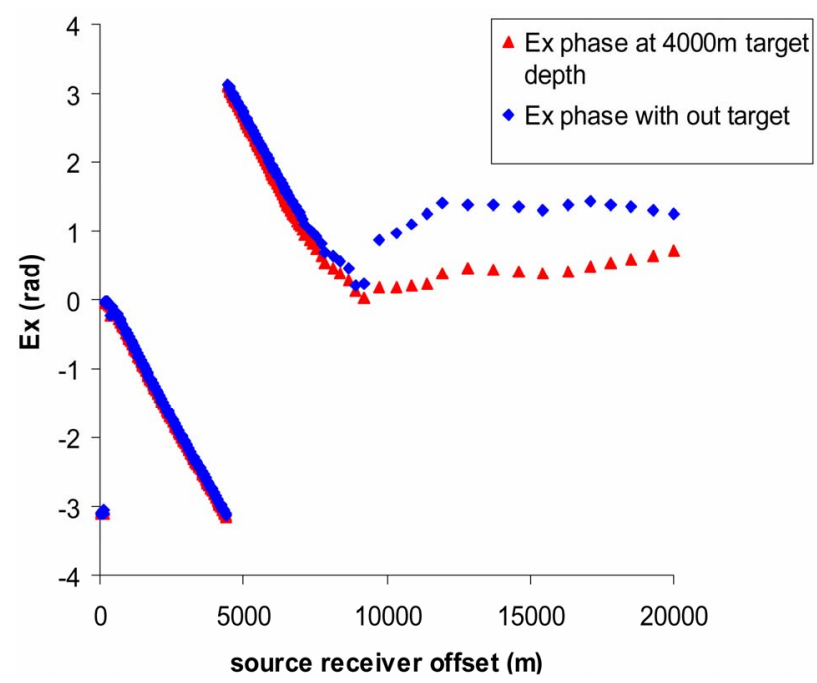

(d)

Figure 6. Direct, guided and reflected waves behavior of Ex field at (a) $1000 \mathrm{~m}$ target depth and (b) $4000 \mathrm{~m}$ target depth and Ex phase at (c) $1000 \mathrm{~m}$ target depth and (d) $4000 \mathrm{~m}$ target depth with and without HC with and without HC using finite element method.

was seen due to shallow target, where as the target depth increases the guided response decreases. At the target depth of $4000 \mathrm{~m}$, no guided response was seen (Figure 6(b)). New EM antenna at $4000 \mathrm{~m}$ target depth gives guided response of EM waves with better delineation up to $10.3 \%$. It was investigated that the guided wave response is greater and can be comparable to the target depth at $1500 \mathrm{~m}$ from seafloor.

Phase verses offset (PVO) study was done to see the variation in phase of the electromagnetic (EM) response from receivers on the seabed. PVO analysis was done for data analysis and for quality control. PVO response also 
provides changes in resistivity which can be helpful for the verification of the MVO results. Phase with the source receiver offset are also investigated Figures 6(c) and (d). It was investigated that phase at $1000 \mathrm{~m}$ gave $78.7 \%$ delineation response where as at $4000 \mathrm{~m}$ target depth $3.64 \%$ Figures 6(c) and (d). It was observed that as target depth increased from $1000 \mathrm{~m}$ to $4000 \mathrm{~m}$, the electromagnetic signal attenuates rapidly [1]. Table 5 shows the comparison between Ex phase with source receiver offset with and without hydrocarbon at target depth changes from $1000 \mathrm{~m}$ to $4000 \mathrm{~m}$. It was found that Ex phase shows better delineation (38.3\%) with and without HC by using 9 magnetic feeders at EM antenna (Table 5).

Figures 7(a)-(g) show normalized $\mathrm{H}$ field response with and without hydrocarbon located at $1000 \mathrm{~m}, 1500 \mathrm{~m}$, $2000 \mathrm{~m}, 2500 \mathrm{~m}, 3000 \mathrm{~m}, 3500 \mathrm{~m}$ and $4000 \mathrm{~m}$ below the seafloor respectively. It was found that normalized $\mathrm{H}$ field at the offset decreased as the depth increased from $1000 \mathrm{~m}$ to $4000 \mathrm{~m}$. It can be seen that at target depth of $1000 \mathrm{~m}$ normalized $\mathrm{H}$ field response was $31.3 \%$ but as the depth increased up to $4000 \mathrm{~m}$, $\mathrm{H}$ field response decreased up to $(2.54 \%)$. Comparison of percentage of normalized E field with and without hydrocarbon with different target depths are given in Table 4. It was found that at 4000 $\mathrm{m}$ target depth with $0.125 \mathrm{~Hz}$ frequency and 1250 A current, it was not possible to see the hydrocarbon. The frequency was decreased from $0.125 \mathrm{~Hz}$ to $0.0625 \mathrm{~Hz}$ at $1250 \mathrm{~A}$; the delineation response of $3.82 \%$ was investigated. The decrease in frequency from $0.125 \mathrm{~Hz}$ to $0.0625 \mathrm{~Hz}$ gives us delineation but resolution will be not good at the low frequency. Novel EM antenna with 3, 6 and 9 magnetic feeders was used for deep hydrocarbon survey. EM antenna with 9 magnetic feeders has shown promising results for the direct hydrocarbon detection below $4000 \mathrm{~m}$ from the seabed (Figure 7(h)). It was investigated that by using 9 magnetic feeders at the antenna, we can get better delineation up to $15.1 \%$ (Table 4).

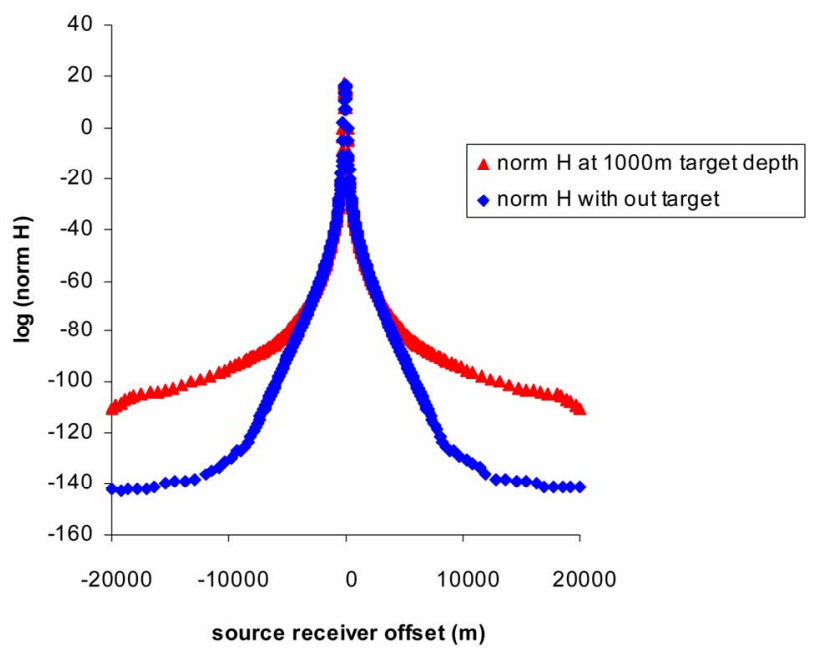

(a)

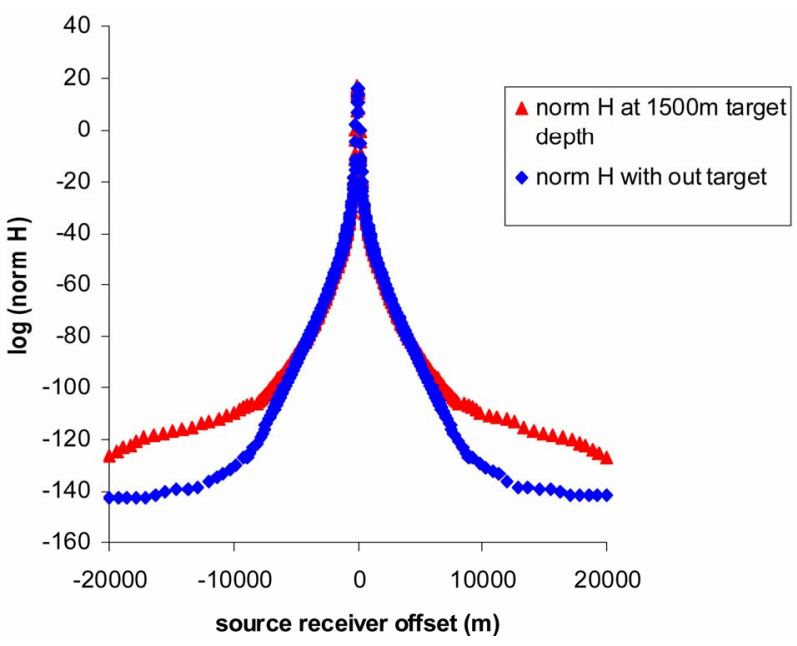

(b)

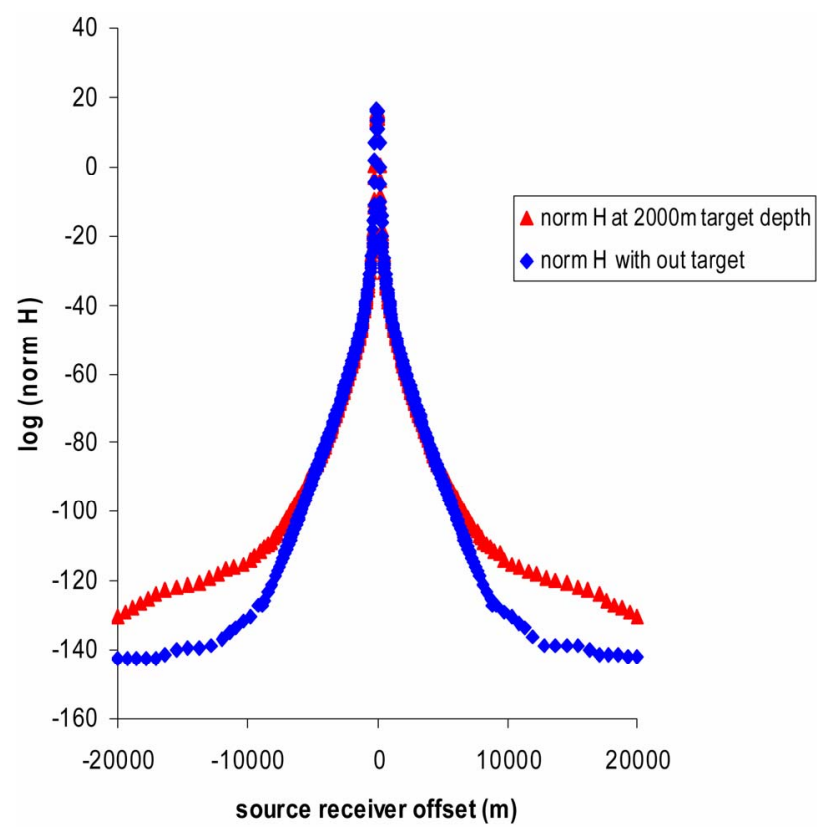

(c)

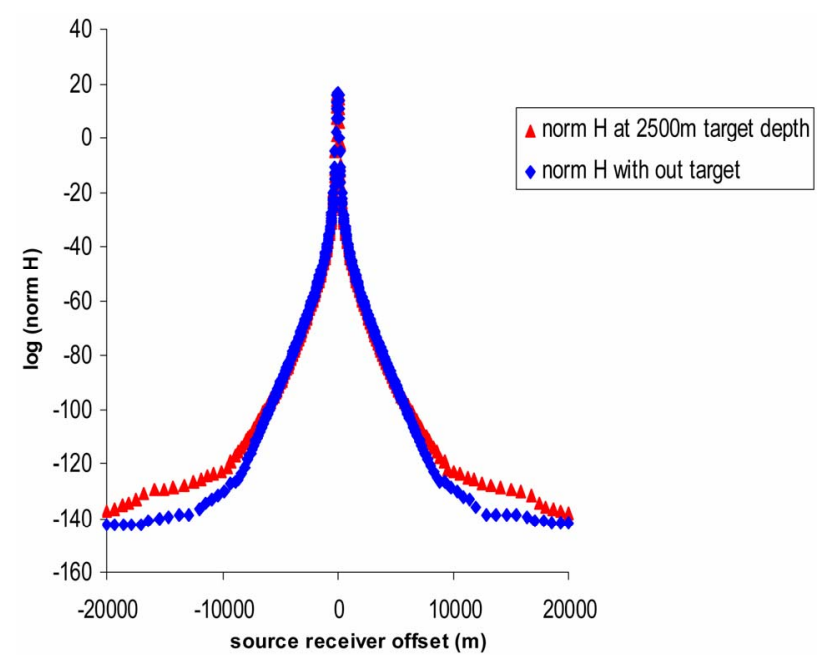

(d) 


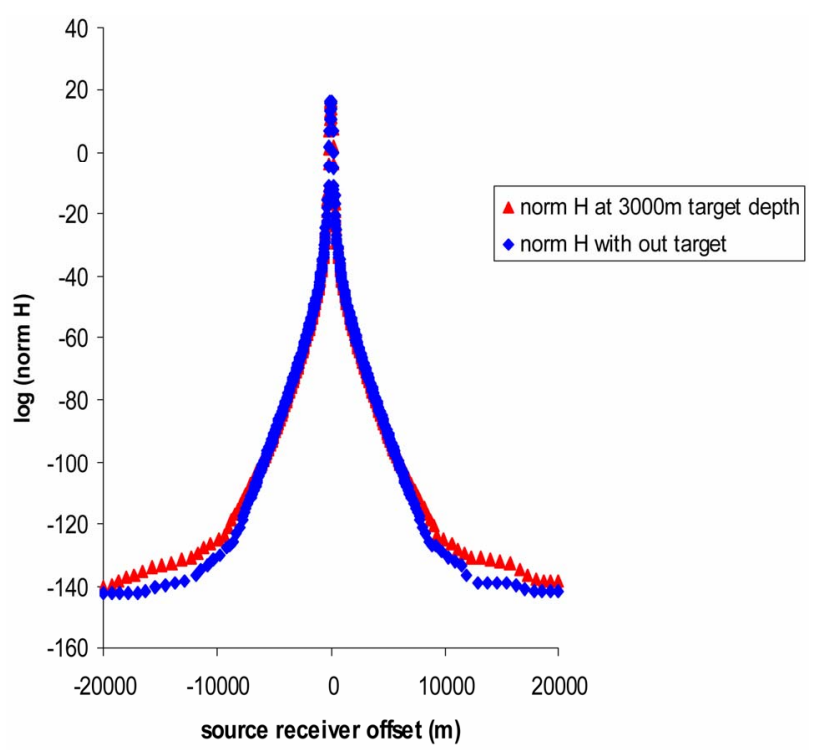

(e)

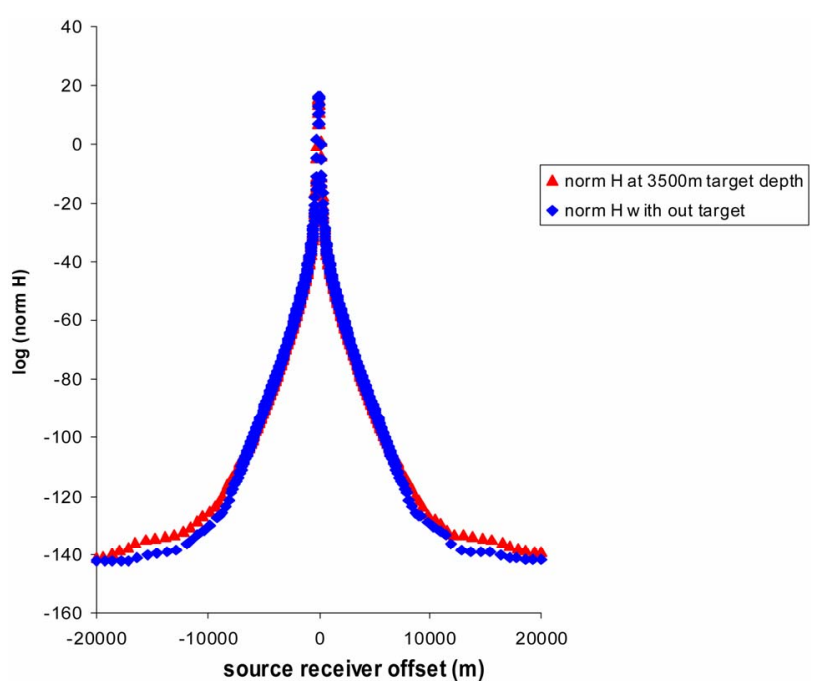

(f)

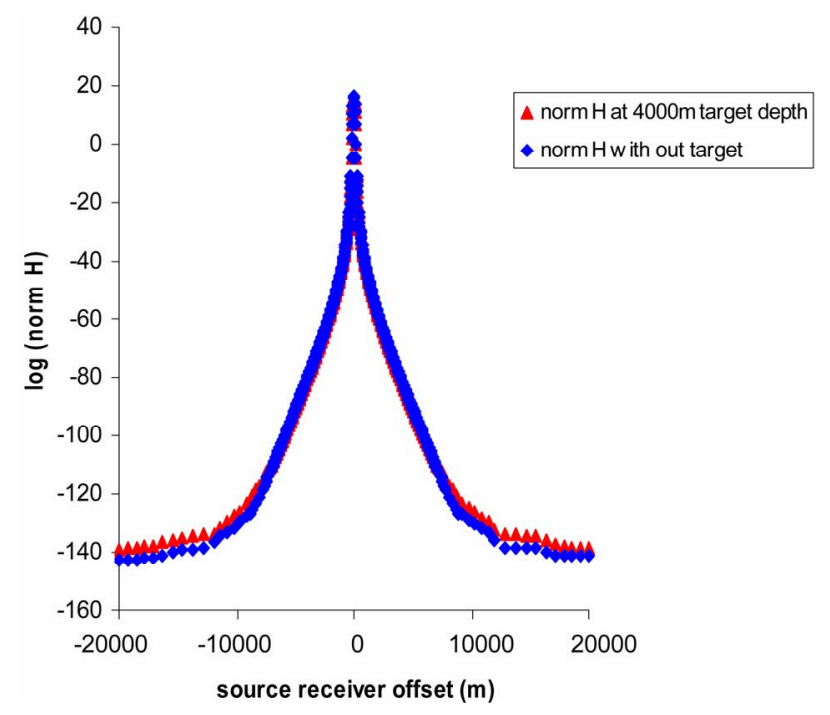

(g)

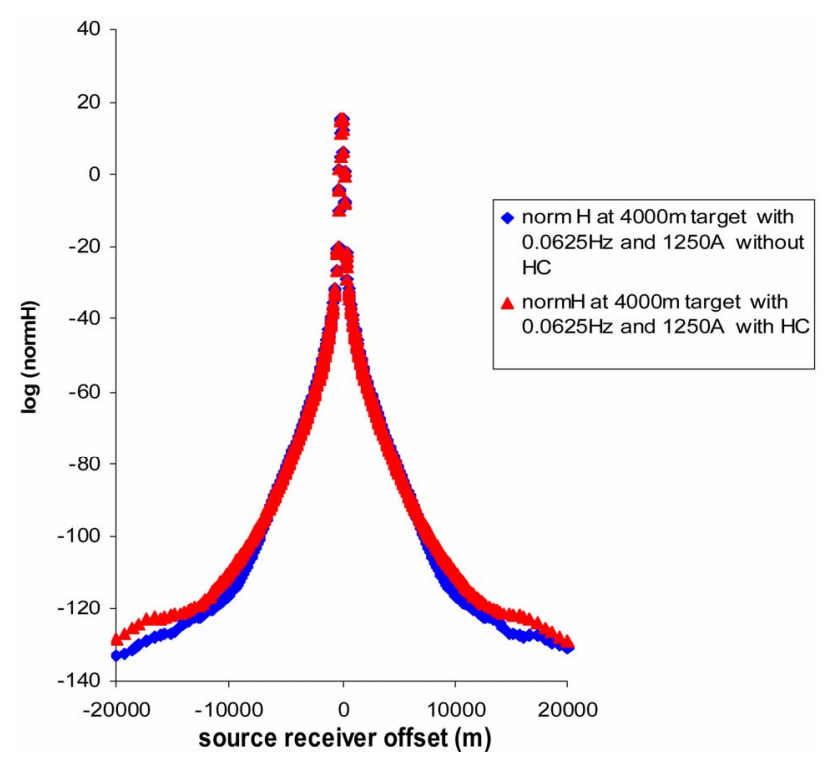

(h)

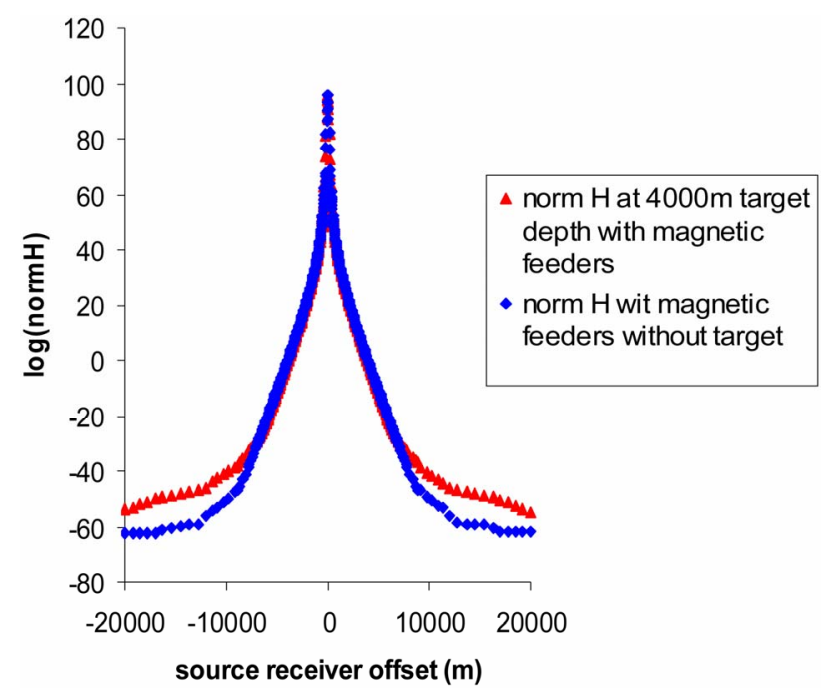

(i)

Figure 7. Magnitude of $\mathrm{Hz}$ phase verses source receiver offset with and without HC at (a) $1000 \mathrm{~m}$; (b) $1500 \mathrm{~m}$; (c) $2000 \mathrm{~m}$; (d) $2500 \mathrm{~m}$; (e) $3000 \mathrm{~m}$; (f) $3500 \mathrm{~m}$; (g) $4000 \mathrm{~m}$ at $0.125 \mathrm{~Hz}$; (h) $4000 \mathrm{~m}$ target at 0.0625 and (i) with 9 magnetic feeders using finite element method.

Similarly, guided response of electromagnetic waves from hydrocarbon was also investigated. It was observed that direct response of electromagnetic waves were detected by the receivers on the seafloor was up to $3.5 \mathrm{~km}$. After $3.5 \mathrm{~km}$ guided response was detected by the receivers. The guided response starts from $3.5 \mathrm{~km}$ to $18 \mathrm{~km}$ where as refracted and reflected wave response can be seen at far offset above $18 \mathrm{~km}$. Figure 8(a) shows the EM response (direct, guided and reflected or refracted) at the target depth $1000 \mathrm{~m}$ below seafloor. The greater guided response was seen due to shallow target, where as the target depth increases the guided response decreases. 


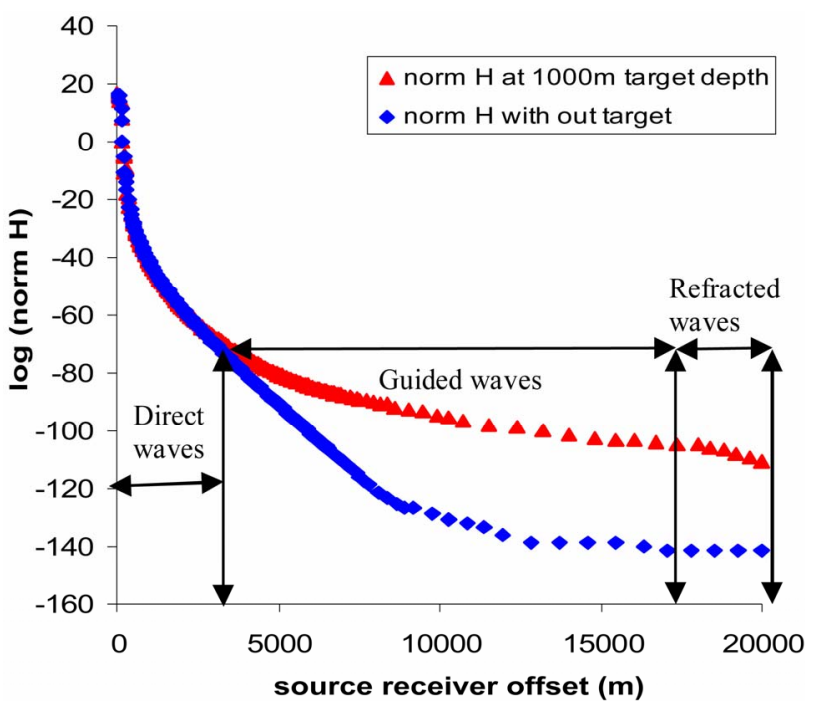

(a)

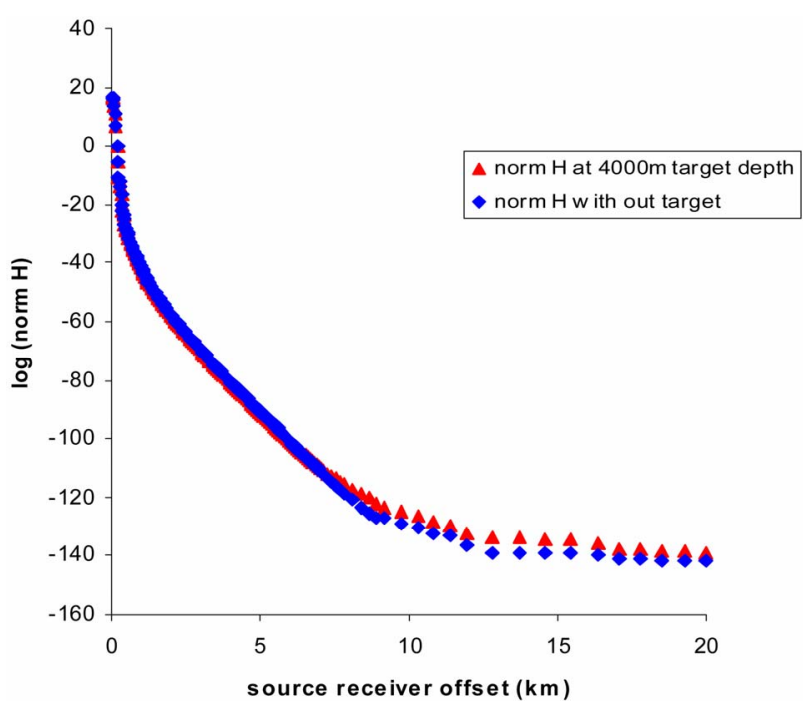

(b)

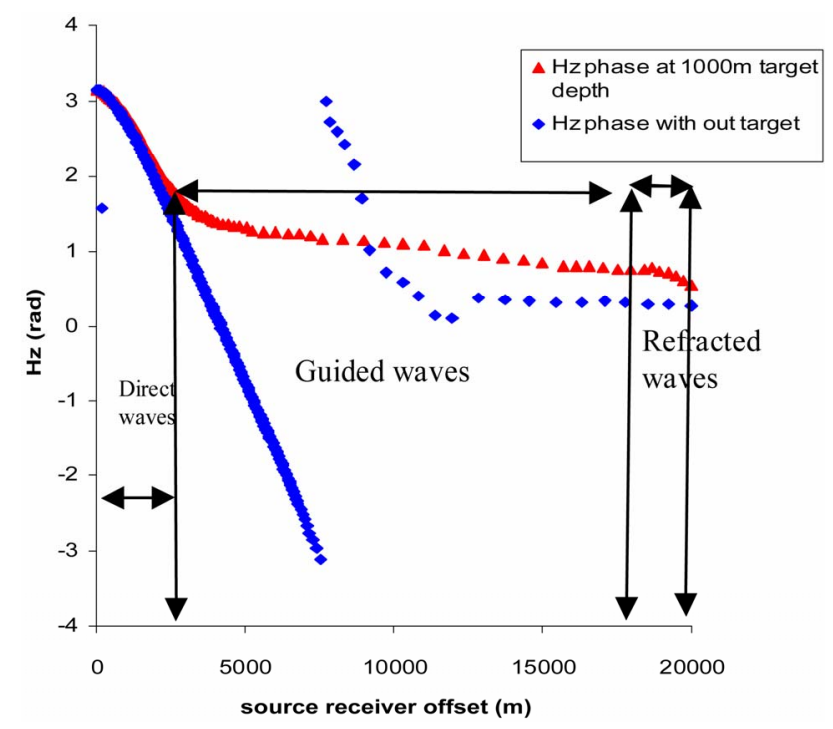

(c)

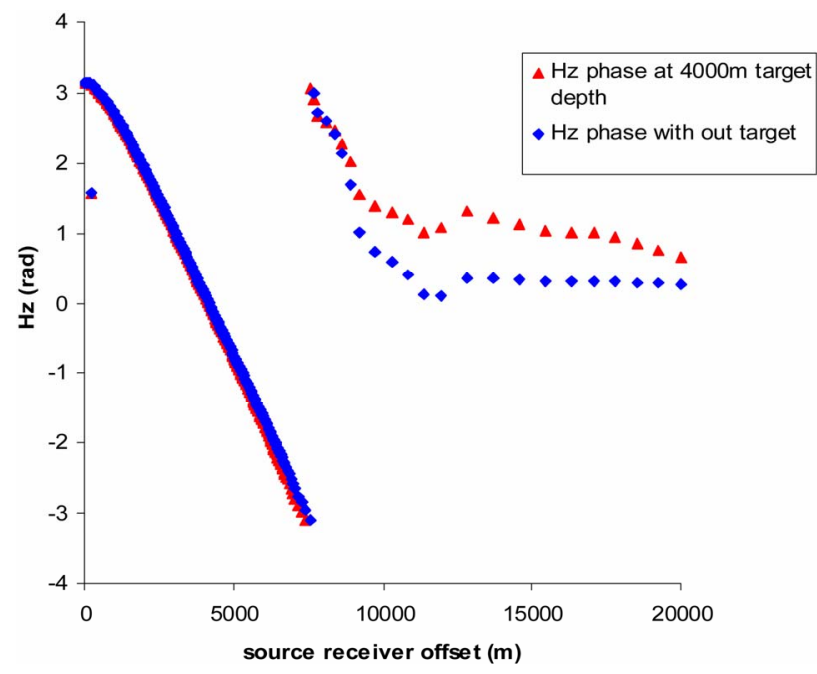

(d)

Figure 8. Direct, guided and reflected waves behavior of $\mathbf{H z}$ field at (a) $1000 \mathrm{~m}$ target depth and (b) $4000 \mathrm{~m}$ target depth and $\mathrm{Hz}$ phase at (c) $1000 \mathrm{~m}$ target depth and (d) $4000 \mathrm{~m}$ target depth with and without HC using finite element method.

At the target depth of $4000 \mathrm{~m}$, no guided response was seen (Figure 8(b)). New EM antenna at $4000 \mathrm{~m}$ target depth gives guided response of EM waves with better delineation up to $15.1 \%$. It was investigated that the guided wave response is greater and can be comparable to the target depth at $1500 \mathrm{~m}$ from seafloor.

Phase with the source receiver offset are also investigated Figures 8(c) and (d). It was observed that percentage difference in phase also decreased as the target depth increased from $1000 \mathrm{~m}$ to $4000 \mathrm{~m}$. It was investigated that phase at $1000 \mathrm{~m}$ gave $164.3 \%$ delineation response where as at $4000 \mathrm{~m}$ target depth $4.32 \%$ (Figures 8(c) and (d)). Table 5 shows the comparison between $\mathrm{Hz}$ phase with source receiver offset with and without hydrocarbon at target depth changes from $1000 \mathrm{~m}$ to 4000 $\mathrm{m}$. It was found that $\mathrm{Hz}$ phase shows better delineation (128.4\%) with and without HC by using 9 magnetic feeders at EM antenna (Table 5).

Current EM antenna used by the industry for seabed logging survey has been used for the hydrocarbon up to 2 $\mathrm{km}$ to $2.5 \mathrm{~km}$ below the seafloor. The $\mathrm{E}$ and $\mathrm{H}$ field were selected to see the delineation response from the seabed environment. It has been found that at target depth of $1500 \mathrm{~m}$ below the seafloor the E field response was 10\% where as $\mathrm{H}$ field response was $16 \%$, where as the target depth increased delineation response was decreased. In our proposed seabed model, at $0.125 \mathrm{~Hz}$ frequency and 1250 A current, it is possible to detect hydrocarbon with delineation of $10.4 \%$ of $\mathrm{E}$ field and $16.3 \%$ of $\mathrm{H}$ field at the target depth of $1500 \mathrm{~m}$ below the seafloor. The values of percentages in delineation are very close to the real seabed logging survey delineation response. It has been 
observed that as the target depth increased the delineation response decreased. This is due to the week signals from hydrocarbon detected by the receivers at the seafloor. It is highly needed to increase the strength of the antenna. In this research work, the antenna was modified using magnetic feeders (prepared from novel magnetic materials). The magnetic feeders were used to excite the TM components such as $\mathrm{H} \phi, \mathrm{Ez}$, and $\mathrm{E} \rho$. When the magnetic feeders were used on the antenna (conductor), the magnetic flux energy will be transferred from magnetic feeders to the current flowing along the antenna conductor. Higher values of Q gave better efficiency of the power which is delivered to the antenna current. When toroidal core is excited by using AC source then due to magnetization magnetic field $\mathrm{H}$ generated. Magnetic field " $\mathrm{H}$ " generated around the full loop constraint entire field to the core material (Biot and Savarts law). Electric field is concentrated at the middle of the magnetic feeder due to the trapped magnetic field inside the circular loop which is due to the Maxwell's relations ( $E$ is perpendicular to the $\mathrm{H}$ field). When a conductor is placed at the point of concentrated electric field, a large amount of current is induced in the wire conductor antenna [5].

The magnetic feeders play an important role for the excitation of electromagnetic antenna. The antenna with magnetic feeders has been used for deep target survey. It has been investigated that by using 3 magnetic feeders it is possible to detect the hydrocarbon reservoir with $\mathrm{E}$ and $\mathrm{H}$ field delineation response up to $3.89 \%$ and $4.25 \%$ respectively. This is still risking factor to drill the well for the industry due to high cost in oil well drilling. The numbers of magnetic feeders are increased from 3 to 6 magnetic feeders and it has been investigated that delineation response increased from $5.41 \%$ to $7.68 \%$ for $\mathrm{E}$ and $\mathrm{H}$ field respectively. The delineation responses gave very close values for $\mathrm{Ex}$ and $\mathrm{Hz}$ fields for our new EM antenna with 9 magnetic feeders when the target was at $1500 \mathrm{~m}$ which is in accord with the current industrial practice. In comparison of the $\mathrm{E}$ and $\mathrm{H}$ field responses, it can be seen that the $\mathrm{H}$ field and phase gave better delineation responses with a higher magnitude which was due to the amplitude of the magnetic field decreasing approximately by $1 / R^{2}$, whereas the electric field amplitude decreased by $1 / R^{3}$ [19]. Table 5 also shows the Ex, $\mathrm{Hz}$ field and phase response at the target depth of $4000 \mathrm{~m}$ by using 12 magnetic feeders at the EM antenna. The delineation response decreased due to the threshold values of the increased magnetic feeders at the EM antenna. The simulation results of antenna with 9 magnetic feeders show good results for $\mathrm{E}$ and $\mathrm{H}$ field delineation response $(10.3 \%$ and $15.1 \%)$ at $4000 \mathrm{~m}$ target depth. The results are in accord with the $\mathrm{E}$ and $\mathrm{H}$ field response at $1500 \mathrm{~m}$ target depth for our proposed model and with current industrial antenna used for seabed logging survey. EM antenna with magnetic feeders has an ability to detect
Table 5. Comparison of Ex and $\mathrm{Hz}$ field and phase with and without hydrocarbon at $4000 \mathrm{~m}$ target depth with $3,6,9$ and 12 magnetic feeders.

\begin{tabular}{cccccccc}
\hline \multirow{2}{*}{$\begin{array}{c}\text { Target } \\
\text { depth }(\mathrm{m})\end{array}$} & $\begin{array}{c}\text { Frequency } \\
(\mathrm{Hz})\end{array}$ & $\begin{array}{c}\text { Current } \\
(1250 \mathrm{~A})\end{array}$ & $\begin{array}{c}\mathrm{Ex} \\
\text { field }\end{array}$ & $\begin{array}{c}\mathrm{Ex} \\
\text { phase }\end{array}$ & $\begin{array}{c}\mathrm{Hz} \\
\text { field }\end{array}$ & $\begin{array}{c}\mathrm{Hz} \\
\text { phase }\end{array}$ \\
\hline 4000 & 0.1250 & $\begin{array}{c}3 \text { magnetic } \\
\text { feeders }\end{array}$ & 3.89 & 5.69 & 4.25 & 16.9 \\
4000 & 0.1250 & $\begin{array}{c}6 \text { magnetic } \\
\text { feeders }\end{array}$ & 5.41 & 15.2 & 7.68 & 94.1 \\
4000 & 0.1250 & $\begin{array}{c}9 \text { magnetic } \\
\text { feeders }\end{array}$ & 10.3 & 38.3 & 15.1 & 128.4 \\
4000 & 0.1250 & $\begin{array}{c}12 \text { magnetic } \\
\text { feeders }\end{array}$ & 8.91 & 30.2 & 11.3 & 116.8 \\
\hline
\end{tabular}

hydrocarbon in deep water and deep target environment due to its better stability.

\section{Conclusion}

Novel EM antenna was successfully used for the deep target hydrocarbon detection $4000 \mathrm{~m}$ below seabed. It was observed that $0.125 \mathrm{~Hz}$ frequency can be able to show better resistivity contrast of $\mathrm{Hz}$ field (31.3\%) and $\mathrm{E}$ field (16.4\%) for our proposed model. It was analyzed that field response delineation decreases as target depth increases from $1000 \mathrm{~m}$ to $4000 \mathrm{~m}$. From the results, it was observed that at the target depth of $4000 \mathrm{~m}$ below seabed no $\mathrm{H}$ field delineation response was seen from the current used antenna by the industry. New EM antenna has been used to see the EM response for deep target detection. It was investigated that novel EM antenna shows better delineation for $\mathrm{E}$ and $\mathrm{H}$ field up to $10.3 \%$ and $15.1 \%$ respectively with and without hydrocarbon. New EM antenna has also an ability to show better $\mathrm{Hz}$ phase delineation response (128.4\%) than the Ex phase response (38.3\%). 3D FEM can provide helpful information for the development of instruments used for the detection of hydrocarbon in CSEM environment.

\section{REFERENCES}

[1] S. Ellingsrud, T. Eidesmo and S. Johansen, "Remote Sensing of Hydrocarbon Layers by Seabed Logging (SBL): Results from a Cruise Offshore Angola,” The Leading Edge, Vol. 21, No. 10, 2002, pp. 972-982. doi:10.1190/1.1518433

[2] F. N. Kong, H. Weterdahl, S. Ellingsrud, T. Eidesmo and S. Johansen, "Seabed Logging: A Possible Direct Hydrocarbon Indicator for Deepsea Prospects Using EM Energy,” Oil and Gas Journal, Vol. 100, No. 19, 2002, pp. 30-38.

[3] M. N. Akhtar, N. Yahya, H. Daud, A. Shafie, H. M. Zaid, M. Kashif and N. Nasir, "Development of EM Wave Guide Amplifier Potentially Used for Sea Bed Logging," Journal of Applied Science, Vol. 11, No. 7, 2011, pp. 1361-1365. doi:10.3923/jas.2011.1361.1365

[4] N. Nasir, N. Yahya, M. N. Akhtar, M. Kashif, A. Shafie, H. Daud and H. M. Zaid, "Magnitude Versus Offset Study with EM Transmitter in Different Resistive Medium," 
Journal of Applied Science, Vol. 11, No. 7, 2011, pp. 1309-1314. doi:10.3923/jas.2011.1309.1314

[5] F. N. Kong, H. Westerdahl and F. Antonsen, "Excitation of a Long Wire Antenna-Antennas from $200 \mathrm{MHz}$ to 1 Hz," Tenth International Conference on Ground Penetrating Radar, Delft, 21-24 June 2004, pp. 137-140.

[6] N. Yahya and T. Zhu, "Development of $\mathrm{Y}_{3} \mathrm{Fe}_{5} \mathrm{O}_{12}$ NanoMagnetic Feeder for Em Source of an Intelligent Horizontal Twin Dipoles,” American Institute of Physics, Vol. 1136, 2009, pp. 269-276.

[7] M. N. Akhtar, N. Yahya and N. Nasir, "Novel EM Antenna Based on $\mathrm{Y}_{3} \mathrm{Fe}_{5} \mathrm{O}_{12}$ Magnetic Feeders for Improved MVO," Electronics, Communications and Photonics Conference, 2011 Saudi International, 24-26 April 2011, pp. 1-6.

[8] N. Yahya, M. N. Akhtar, N. Nasir, A. Shafie, M. S. Jabeli and K. Koziol, "CNT Fibres/Aluminium-NiZnFe $\mathrm{O}_{4}$ Based EM Transmitter for Improved Magnitude vs Offset (MVO) in a Scaled Marine Environment," Journal of Nanoscience and Nanotechonology, Vol. 11, No. 7, 2011, pp. 1-7.

[9] M. N. Akhtar, N. Yahya, K. Koziol and N. Nasir, "Synthesis and Characterizations of $\mathrm{Ni}_{0.8} \mathrm{Zn}_{0.2} \mathrm{Fe}_{2} \mathrm{O}_{4^{-}}$ MWCNTs Composites for Their Application in Sea Bed Logging," Ceramics International, Vol. 37, No. 8, 2011, pp. 3237-3245. doi:10.1016/j.ceramint.2011.05.113

[10] N. O. Sadiku, "Numerical Methods in Electromagnetics," 2nd Edition, Mathew, Boca Raton, London, New York, Washington DC, 2001.

[11] M. Deng, W. B. Wei, W. B. Zhang, Y. Sheng, Y. J. Li and M. Wang, "Electric Field Responses of Different Gas Hydrate Models Excited by a Horizontal Electric Dipole Source with Changing Arrangements," Petroleum Exploration \& Development, Vol. 37, No. 4, 2010, pp. 438-442.
[12] E. A. Badea, M. E. Everett, G. A. Newman and O. Biro, "Finite-Element Analysis of Controlled-Source Electromagnetic Induction Using Coulomb Gauged Potentials," Geophysics, Vol. 66, No. 3, 2001, pp. 786-799. doi:10.1190/1.1444968

[13] F. Sugeng, A. Raiche and G. Wilson, “An Efficient Compact Finite-Element Modelling Method for the Practical 3D Inversion of Electromagnetic Data from High Contrast Complex Structures," IAGA WG 1, 2 on Electromagnetic Induction in Earth, Spain, September 2006, pp. 17-23.

[14] J. Park, T. I. Bjornara, H. Westerdahl and E. Gonzalez, "On Boundary Conditions for CSEM Finite Element Modeling. I,” Proceedings of the Comsol Conference, Hannover, 2008, pp. 1-4.

[15] F. N. Kong, S. E. Johnstad, T. Røsten and H. Westerdahl, "A 2.5D Finite Element Modeling Method for Marine CSEM Modeling in Stratified Anisotropic Media," Geophysics, Vol. 73, No. 1, 2008, pp. F9-F19. doi:10.1190/1.2819691

[16] C. G. Farquharson, "Numerical Modeling for Geophysical Electromagnetic Methods," Memorial University of Newfoundland, St. Johns, 2009.

[17] D. S. Parasins, "Principles of Applied Geophysics," 5th Edition, Chapman \& Hall, London, 1997.

[18] J. D. King, "Using a 3D Finite Element Forward Modelling Code to Analyze Resisitive Structures with Controlled Source Electromagnetics in a Marine Environment," Master's Thesis, Texas A\&M University, College Station, 2004.

[19] E. S. Um, "On the Physics of Galvanic Source Electromagnetic Geophysical Methods for Terrestrial and Marine Exploration," University of Wisconsin Madison, Madison, 2005. 